\title{
What are the Economic Costs to Society Attributable to Alcohol Use? A Systematic Review and Modelling Study
}

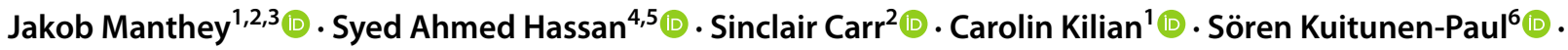 \\ Jürgen Rehm ${ }^{1,2,4,7,8}$ (D)
}

Accepted: 12 April 2021 / Published online: 10 May 2021

(c) The Author(s) 2021

\begin{abstract}
Background Alcohol-attributable costs to society are captured by cost-of-illness studies, however estimates are often not comparable, e.g. due to the omission of relevant cost components. In this contribution we (1) summarize the societal costs attributable to alcohol use, and (2) estimate the total costs under the assumption that all cost components are considered.

Methods A systematic review and meta-analyses were conducted for studies reporting costs from alcohol consumption for the years 2000 and later, using the EMBASE and MEDLINE databases. Cost estimates were converted into 2019 international dollars (Int\$) per adult and into percentage of gross domestic product (GDP). For each study, weights were calculated to correct for the exclusion of cost indicators.

Results Of 1708 studies identified, 29 were included, and the mean costs of alcohol use amounted to 817.6 Int $\$$ per adult (95\% confidence interval [CI] 601.8-1033.4), equivalent to 1.5\% of the GDP (95\% CI 1.2-1.7\%). Adjusting for omission of cost components, the economic costs of alcohol consumption were estimated to amount to 1306 Int\$ per adult (95\% CI $873-1738$ ), or $2.6 \%$ (95\% CI 2.0-3.1\%) of the GDP. About one-third of costs (38.8\%) were incurred through direct costs, while the majority of costs were due to losses in productivity (61.2\%).

Discussion The identified cost studies were mainly conducted in high-income settings, with high heterogeneity in the employed methodology. Accounting for some methodological variations, our findings demonstrate that alcohol use continues to incur a high level of cost to many societies.
\end{abstract}

Registration PROSPERO \#CRD42020139594.

\section{Key Points}

Alcohol incurs substantial costs to societies, including in middle-income countries.

A methodology is proposed to estimate total costs while accounting for omitted cost components.

If all cost components were to be considered, the economic costs of alcohol consumption would amount to 1306 international dollars (Int\$) per adult (95\% confidence interval 873-1738), 1872 Int\$ per drinker (95\% CI 1279-2466), or equivalent to $2.6 \%$ (95\% CI $2.0-3.1 \%$ ) of the gross domestic product.

Jakob Manthey

jakob.manthey@tu-dresden.de

Extended author information available on the last page of the article

\section{Introduction}

Alcohol use has been identified as a major risk factor for burden of disease [1-3], leading to the introduction of reduction goals in major $\mathrm{UN}$ and other international frameworks, such as the Sustainable Development Goals [4, 5]. However, alcohol consumption differs from many other risk factors, as attributable health burden is not restricted to the drinker alone but also extends to others, including those who have abstained from alcohol during their lifetime (e.g. via drunk driving or maternal alcohol consumption [6]). Furthermore, harm attributable to alcohol is not restricted to health but comprises many other aspects of life and sustainable development, such as criminal behaviour [7] and loss of economic productivity (e.g. Rehm et al. and Thavorncharoensap et al. [8,9]). A recent WHO report describes how alcohol consumption undermines commitments to achieve 13 of the 17 UN Sustainable Development Goals, by impacting on not only a range of 
health-related indicators but also on economic and social development, the environment, and equality [10].

Given the adverse consequences of alcohol consumption, numerous studies have tried to summarize different impacts of alcohol on harm to society, and economic cost studies have proven to be an important way to achieve this goal [11]. Summaries of such studies were published more than a decade ago $[8,9]$ (for a systematic review restricted to the European Union, see Barrio et al. [12]), while several dozen additional studies have been published since [13]. Thus, an update of these reviews and their conclusions seems warranted.

A recent systematic literature search has found that economic cost studies differ widely in the cost components included [13], both with respect to direct and indirect costs and to subcategories (see Single et al. [11] for definitions). In fact, differences in the methodology of cost studies were identified as a major hindrance to comparing estimates over time and between locations [14]. Thus, in addition to summarizing cost studies, we aimed to present an estimation for all economic costs under the assumption that all relevant components are included. To our knowledge, this is the first such attempt to account for methodological differences in estimating the economic costs of alcohol or other substances. Thus, the aims of the current review were twofold:

1. To summarize the economic costs for societies attributable to alcohol consumption, differentiating for available subcategories.

2. To estimate the costs for a hypothetical scenario in which all relevant components are included.

\section{Methods}

\subsection{Search Strategy and Selection Criteria}

We aimed to include all studies estimating the societal costs attributable to alcohol consumption for the year 2000 or later, excluding all studies that limited the estimates to subgroups of drinkers, such as those with alcohol dependence. Following the Preferred Reporting Items for Systematic Reviews and Meta-Analyses (PRISMA) guidelines [15], electronic searches were performed on the MEDLINE and EMBASE databases, and additional studies were identified through a reference scan and expert suggestions. The systematic literature search was conducted in March 2019, updated in July 2020, and resulted in a total of 1708 studies. The following terms were used in the systematic search: 'costs and cost analysis', 'cost-benefit analysis', 'cost of illness', 'health care costs', 'health expenditures', 'alcohol drinking', 'alcoholic intoxication', 'alcoholism', 'binge drinking', 'alcoholic beverages', and 'heavy drinking'. In addition to these terms, terms including dependence, disorder, and consumption were searched for within the three words adjacent on either side of the word 'alcohol', while variations of illness, sickness, disease, social, societal, or analysis were searched for within the three words adjacent on either side of the word 'cost'. Additionally, studies were identified through reference scans and expert suggestions. The search strategy and review procedures were registered with PROSPERO [16] (registration \# CRD42020139594). For details on study bias assessment, see electronic supplementary material (ESM) 1 and 2.

\subsection{Data Extraction and Additional Data Sources}

For each study, data were first extracted by one person and then independently checked by another person for accuracy. $\mathrm{JM}$ was responsible for resolving discrepancies. For each study, the estimated costs were extracted into a classification scheme determined in a previous study [13]. The scheme was characterized by four levels of cost components: (1) total costs; (2) categories within level 1 (total costs), i.e. direct, indirect, intangible, and saved costs; (3) categories within each level 2 category (e.g. health care costs as part of direct costs); and (4) categories within each level 3 subcategory (e.g. hospitalization costs as part of health care costs).

We gathered further information on gross domestic product (GDP) and on the prevalence of past-year drinkers from the studies or from external sources if not reported. Other required covariates were adult population size (15 years or older) for the respective jurisdiction, alcohol per capita consumption - an indicator for population alcohol exposure, and regional grouping of countries/locations (henceforth, locations). For definitions and sources, see ESM 1.

\subsection{Calculation of Costs Attributable to Alcohol Use}

We calculated two indicators to compare the economic costs attributable to alcohol use across different countries and years. First, we (1) inflated local currency cost estimates to 2019 values based on World Bank Consumer Price Index data [17]; (2) converted these figures into 2019 international dollars (Int\$) using World Bank conversion factors [17]; and (3) divided the result by the adult population size (aged 15 years or older) for the year for which costs were estimated. In other words, this measure described the tangible costs attributable to alcohol in 2019 Int \$ per adult. Second, we calculated a cost equivalent as a percentage of the GDP by dividing the estimated costs by the location-specific GDP of the same year for which costs were estimated.

To summarize cost estimates, we considered performing a random-effects meta-analysis. However, only eight studies reported measures of uncertainty around selected 
point estimates and no single study reported measures of uncertainty for all estimates. As the measures of uncertainty constitute one of the two sources of variation required for random-effects meta-analyses, we relied only on the other source of variation, i.e. the difference in the methodology in estimating costs. To achieve this, we calculated weights for each study describing the proportion of all possible costs included, ranging from 0 to 1 . These weights represented not only an indicator of study quality but further served to estimate the tangible costs under the assumption that all relevant cost indicators were included in the estimates. The calculation of weights started at the lowest level of costs (for a definition of cost levels, see above). First, the relative contribution of each cost category was determined by the share of costs determined by each category, averaged over all studies. For example, we calculated how much direct costs are driven by hospitalization costs in all studies. This was repeated for all categories of the same level, e.g. outpatient or medication costs. Second, we summarized how many of the possible cost categories at this level were considered in each study, weighted by the relative contribution of each category (calculated in the first step). This resulted in the study-specific weight for level 3 (in this example, health care costs). By repeating this procedure, we accounted for the inclusion of all relevant cost categories at each level for each study. For more details on weight calculation, see ESM 1.

For the two cost indicators (Int\$ per adult; \% GDP) and separately for the total costs, and the direct and indirect costs, weighted means were calculated to estimate average costs across all studies. The variation around point estimates is given by $95 \%$ confidence intervals (CIs) based on the standard error. Cluster effects were assessed through intraclass correlation coefficients (ICC) of random intercept regression models using the $\mathrm{R}$ packages lmer [18] and performance [19].

\subsection{Additional Analyses}

In additional analyses, we (a) examined the correlation of the two cost indicators; (b) estimated costs for a scenario in which all relevant cost drivers are considered; and (c) tested the association of costs with alcohol consumption variables using a number of regressions with switching dependent and independent variables.

For (a), we used the two cost indicators (Int\$ per adult and \% GDP) from all studies reporting both direct and indirect costs and calculated the unweighted Pearson correlation. We repeated the correlation analyses applying study weights in order to account for possible distortions in the correlation introduced by variations in including cost components.

For (b), we divided the costs by the respective study weights, separated for the two cost indicators, thus correcting for omissions of relevant cost components. Subsequently, unweighted means were calculated across all studies.

For (c), we performed linear regressions using the two cost indicators as dependent variables and either alcohol per capita (i.e. annual litres of pure alcohol intake divided by the adult population size) or alcohol per drinker (i.e. annual litres of pure alcohol intake divided by the adult population size who reported alcohol consumption in the past 12 months) as the independent variable, weighted with the study weight (see above and ESM 1 for details). In total, 12 models were performed for (1) two different cost indicators as dependent variables; (2) two different alcohol indicators as independent variables; and (3) for total direct and indirect costs.

All data were processed in $\mathrm{R}$ version 4.0.3 [20] and Microsoft Excel (Microsoft Corporation, Redmond, WA, USA). The complete data and R code are appended to this paper (ESM 3).

\section{Results}

\subsection{Descriptive Data}

After excluding duplicates, a total of 1688 references were screened (see the flow chart [supplementary Fig. 1] in ESM 1), finally resulting in 29 included studies reporting alcohol-attributable tangible costs in the analyses. In 9 studies, intangible costs were estimated, however with quite different and partially incomparable methods (e.g. reporting number of quality-adjusted life-years [QALYs] lost [21] or disability-adjusted life-years [DALYs] [22] or assigning monetary values to lost lives [23]). Similarly, saved costs were rarely estimated ( $n=7$ studies), again with largely different definitions and approaches (e.g. as tax revenue [24] or avoided costs due to the protective effect of low levels of alcohol use on certain diseases [25]). Given the heterogeneity of studies estimating intangible and saved costs, we restricted the analyses to tangible costs, i.e. direct and indirect costs only. The cost indicators for direct and indirect costs are listed and defined in Table 1. A risk-of-bias assessment, conducted by two independent reviewers (with moderate agreement), suggested overall acceptable quality of the studies (5.9 out of 9 possible points; for more details, see ESM 1 and 2).

The majority of studies provided cost estimates for European countries $(n=16)$ or the high-income North America region $(n=7)$, with other regions being underrepresented ( $n=1$ Australasia, $n=1$ high-income Asia Pacific, $n=1$ Southern Sub-Saharan Africa, and $n=3$ South-East Asia) or not presented at all. Almost all studies reported both direct and indirect cost estimates, with two studies providing only direct cost estimates $[26,27]$ and one study providing only 
indirect cost estimates [28]. The majority of studies reported cost estimates for entire countries, while one study referred to 28 European countries [28], and 10 studies provided subnational estimates [29-38]. Only one study estimated costs using a bottom-up approach, i.e. using survey data of a sample of drinkers rather than routine statistics [34]. For an overview of all studies, see Table 2.

\subsection{Total Alcohol-Attributable Costs}

Across 26 studies providing estimates of both direct and indirect costs (see Fig. 1 for estimates from all 29 studies), the mean total costs amounted to 817.6 Int\$ per adult $(95 \%$ CI $601.8-1033.4)$ or 1151.6 Int\$ per adult drinker $(95 \%$ CI 857.0-1446.2). We observed a considerable degree of clustering, with estimates from one location being more similar to each other than to other locations (ICC $=0.914$ ). For example, costs for Germany, despite being estimated 5 years apart, hardly differed (609.6 Int\$ and 608.5 Int\$). However, we did not observe a similar cluster effect at the regional level $(\mathrm{ICC}=0.096)$, despite descriptively higher costs reported, e.g. for Western European countries (922.8 Int\$) compared with Southeast Asian countries (206.4 Int\$; regional differences not significant in weighted linear regression).

Costs were further compared with the GDP of the same year and location. Averaged across the 26 studies that provided estimates on both direct and indirect costs, the alcohol-attributable costs equalled about $1.5 \%$ of the GDP (95\% CI 1.2-1.7\%) [see also supplementary Fig. 2 in ESM 1]. As for costs per adult, the costs expressed as a percentage of the GDP exhibited a high degree of clustering for locations (ICC $=0.911$ ) but not for regions $(\mathrm{ICC}=0.115)$.

\subsection{Share of Direct and Indirect Costs}

Across 26 studies that provided estimates for both direct and indirect costs, $38.8 \%$ (95\% CI 31.3-46.3\%) of the total costs, i.e. 317.2 Int\$ per adult, incurred through direct cost components such as health care, crime, and traffic accidents. The remaining $61.2 \%$ (95\% CI 55.0-71.4\%) of costs (500.4 Int $\$$ per adult) were driven by indirect costs, such as loss of productivity due to workplace absence or premature mortality (see also Fig. 2).

Health care costs made up nearly half of all direct costs (46.2\% of all direct costs; 95\% CI 37.4-55.0\%) and were considered in all of the 28 studies that reported direct costs. Costs related to the criminal justice system were also often considered ( $n=21$ studies; $28.9 \%, 95 \%$ CI $23.5-34.3 \%)$, while traffic accident-related costs $(n=13$ studies; $13.5 \%$, 95\% CI 8.0-19.0\%) and other costs $(n=13 ; 11.4 \%, 95 \%$ CI 6.1-16.7\%) were less frequently estimated (see also Fig. 3).

Estimation of indirect costs also varied greatly across studies (see Fig. 4). In all studies explicitly reporting the approach for estimating indirect costs, most followed the

Table 1 Cost components of the direct and indirect costs of alcohol consumption

\begin{tabular}{|c|c|c|}
\hline \multirow[t]{4}{*}{$\begin{array}{l}\text { Direct costs }=\text { costs that reflect a utilization of } \\
\text { resources }\end{array}$} & Health care & $\begin{array}{l}\text { Health care costs caused by alcohol-attributable health } \\
\text { conditions (e.g. costs of hospitalization) }\end{array}$ \\
\hline & Criminal justice system & $\begin{array}{l}\text { Costs caused by alcohol-attributable crimes (e.g. incar- } \\
\text { ceration costs, police) }\end{array}$ \\
\hline & Traffic & $\begin{array}{l}\text { Costs caused by driving under the influence of alcohol } \\
\text { (e.g. car damage) }\end{array}$ \\
\hline & Other & $\begin{array}{l}\text { Other alcohol-related direct costs (e.g. costs of social } \\
\text { workers) }\end{array}$ \\
\hline \multirow[t]{8}{*}{ Indirect costs $=$ costs that reflect productivity losses } & Health care & $\begin{array}{l}\text { Productivity losses caused by alcohol-attributable hospi- } \\
\text { talization }\end{array}$ \\
\hline & Unemployment & $\begin{array}{l}\text { Productivity losses caused by alcohol-attributable unem- } \\
\text { ployment }\end{array}$ \\
\hline & Absenteeism & $\begin{array}{l}\text { Productivity losses caused by alcohol-attributable } \\
\text { absence from work }\end{array}$ \\
\hline & Presenteeism & Alcohol-attributable productivity losses while working \\
\hline & Household and leisure time & $\begin{array}{l}\text { Alcohol-attributable productivity losses during household } \\
\text { and leisure activities (mostly estimated for the non- } \\
\text { employed population) }\end{array}$ \\
\hline & Premature mortality & $\begin{array}{l}\text { Alcohol-attributable productivity losses at work due to } \\
\text { death before age of retirement }\end{array}$ \\
\hline & Early retirement & $\begin{array}{l}\text { Alcohol-attributable productivity losses at work due to an } \\
\text { inability to work }\end{array}$ \\
\hline & Other & $\begin{array}{l}\text { Other alcohol-attributable indirect costs (e.g. productivity } \\
\text { loss due to incarceration) }\end{array}$ \\
\hline
\end{tabular}


Table 2 Summary of studies including reported cost estimates, and the study weight

\begin{tabular}{|c|c|c|c|c|c|c|c|}
\hline Region/authors & Location & Year & $\begin{array}{l}\text { Costs per adult in } \\
2019 \text { Int\$ }\end{array}$ & $\%$ of GDP & $\%$ Direct & $\%$ Indirect & $\begin{array}{l}\text { Study } \\
\text { weight } \\
(\%)^{\mathrm{a}}\end{array}$ \\
\hline \multicolumn{8}{|l|}{ Australasia } \\
\hline $\begin{array}{l}\text { Collins and Lapsley } \\
\text { [57] }\end{array}$ & Australia & $2004 / 2005$ & 797.5 & 1.7 & 48.9 & 51.1 & 75.8 \\
\hline \multicolumn{8}{|c|}{ High-Income Asia Pacific } \\
\hline Chung et al. [58] & South Korea & 2002 & 530.5 & 1.5 & 8.4 & 91.6 & 64.1 \\
\hline Southeast Asia & & & $206.4(0-787.1)$ & $1.4(0-5.0 \%)$ & & & \\
\hline $\begin{array}{l}\text { Ranaweera et al. } \\
\text { [59] }\end{array}$ & Sri Lanka & 2015 & 178.0 & 1.1 & 43.8 & 56.2 & 36.2 \\
\hline $\begin{array}{l}\text { Thavorncharoensap } \\
\text { et al. [60] }\end{array}$ & Thailand & 2006 & 297.1 & 2.0 & 4.2 & 95.8 & 55.7 \\
\hline Paileeklee et al. [34] & $\begin{array}{l}\text { Thailand (Khon } \\
\text { Khaen) }\end{array}$ & 2007 & 61.3 & 0.6 & 20.4 & 79.6 & 27.7 \\
\hline \multicolumn{5}{|c|}{ Southern Sub-Saharan Africa } & 2.5 & & \\
\hline $\begin{array}{l}\text { Matzopoulos et al. } \\
\text { [23] }\end{array}$ & South Africa & 2009 & 443.2 & 2.5 & 59.9 & 40.1 & 50.5 \\
\hline \multicolumn{3}{|c|}{ High-Income North America } & $\begin{array}{l}967.9(519.7- \\
1416.1)\end{array}$ & \multicolumn{3}{|l|}{$1.5(0.8-2.2)$} & \\
\hline $\begin{array}{l}\text { CSUCH Scientific } \\
\text { Working Group } \\
\text { [47] }\end{array}$ & Canada & 2017 & 469.9 & 0.8 & 59.5 & 40.5 & 67.8 \\
\hline Rehm et al. [40] & Canada & 2002 & 652.7 & 1.2 & 51.0 & 49.0 & 78.5 \\
\hline $\begin{array}{c}\text { Trangenstein and } \\
\text { Jernigan [36] }\end{array}$ & USA (Baltimore) & 2013 & 1277.0 & 1.7 & 18.5 & 81.5 & 73.1 \\
\hline Miller et al. [33] & USA (California) & 2010 & 1462.7 & 1.9 & 35.6 & 64.4 & 27.7 \\
\hline $\begin{array}{l}\text { Bohs and Sayed } \\
\text { [31] }\end{array}$ & USA (Florida) & 2008 & 1675.7 & 2.8 & 39.2 & 60.8 & 66.2 \\
\hline Barkey [29] & USA (Montana) & 2005 & 852.9 & 1.7 & 31.4 & 68.6 & 58.0 \\
\hline Wickizer [38] & $\begin{array}{l}\text { USA (Washington } \\
\text { State) }\end{array}$ & 2005 & 666.9 & 0.9 & 18.8 & 81.2 & 59.8 \\
\hline \multicolumn{3}{|l|}{ Eastern Europe } & $621.5(9.8-1233.2)$ & \multicolumn{3}{|l|}{$2.1(0.7-3.4 \%)$} & \\
\hline Saar [61] & Estonia & 2006 & 645.4 & 2.0 & 18.7 & 81.3 & 55.4 \\
\hline $\begin{array}{l}\text { Potapchik and } \\
\text { Popovich [39] }\end{array}$ & Russian Federation & 2008 & 598.6 & 2.1 & 32.6 & 67.4 & 57.9 \\
\hline \multicolumn{3}{|l|}{ Western Europe } & $\begin{array}{l}922.8(477.1- \\
1368.5)\end{array}$ & \multicolumn{3}{|l|}{$1.3(0.9-1.7 \%)$} & \\
\hline Lievens et al. [22] & Belgium & 2012 & 327.1 & 0.5 & 62.4 & 37.6 & 53.7 \\
\hline $\begin{array}{l}\text { Verhaeghe et al. } \\
\text { [62] }\end{array}$ & Belgium & 2012 & 245.0 & 0.4 & 58.5 & 41.5 & 40.4 \\
\hline $\begin{array}{l}\text { Kopp and Ogrodnik } \\
\text { [24] }\end{array}$ & France & 2010 & 2441.2 & 2.1 & 9.6 & 90.4 & 67.6 \\
\hline $\begin{array}{l}\text { Adams and Effertz } \\
\text { [63] }\end{array}$ & Germany & 2007 & 608.5 & 1.1 & 37.6 & 62.4 & 59.2 \\
\hline $\begin{array}{l}\text { Konnopka and } \\
\text { König [25] }\end{array}$ & Germany & 2002 & 609.6 & 1.2 & 34.6 & 65.4 & 46.6 \\
\hline $\begin{array}{l}\text { Cortez-Pinto et al. } \\
\text { [27] }\end{array}$ & Portugal & 2010 & 415.2 & 1.3 & 100.0 & NA & 9.9 \\
\hline Scandurra [64] & Spain & 2007 & 133.0 & 0.3 & 12.8 & 87.2 & 32.2 \\
\hline Jarl et al. [21] & Sweden & 2002 & 562.0 & 1.1 & 37.4 & 62.6 & 65.9 \\
\hline $\begin{array}{l}\text { Scarborough et al. } \\
\text { [26] }\end{array}$ & UK & 2007 & 163.6 & 0.2 & 100.0 & NA & 16.2 \\
\hline $\begin{array}{l}\text { FGS McClure Wat- } \\
\text { ters [32] }\end{array}$ & $\begin{array}{l}\text { UK (Northern } \\
\text { Ireland) }\end{array}$ & 2009 & 1097.7 & 1.9 & 70.3 & 29.7 & 75.8 \\
\hline
\end{tabular}


Table 2 (continued)

\begin{tabular}{|c|c|c|c|c|c|c|c|}
\hline Region/authors & Location & Year & $\begin{array}{l}\text { Costs per adult in } \\
2019 \text { Int\$ }\end{array}$ & $\%$ of GDP & $\%$ Direct & $\%$ Indirect & $\begin{array}{l}\text { Study } \\
\text { weight } \\
(\%)^{\mathrm{a}}\end{array}$ \\
\hline Beale et al. [30] & UK (Scotland) & 2007 & 1248.6 & 1.6 & 58.6 & 41.4 & 77.1 \\
\hline $\begin{array}{l}\text { Scottish Govern- } \\
\text { ment [35] }\end{array}$ & UK (Scotland) & $2006 / 2007$ & 1064.3 & 1.5 & 54.2 & 45.8 & 75.8 \\
\hline $\begin{array}{l}\text { Varney and Guest } \\
\text { [37] }\end{array}$ & UK (Scotland) & $2001 / 2002$ & 768.2 & 1.2 & 42.0 & 58.0 & 65.1 \\
\hline \multicolumn{8}{|l|}{$E U 28$} \\
\hline Łyszczarz [28] & EU 28 & 2016 & 123.0 & 0.2 & NA & 100.0 & 20.3 \\
\hline Average & & & $\begin{array}{c}817.6(601.8- \\
1033.4)\end{array}$ & $1.5(1.2-1.7 \%)$ & $38.8(31.3-46.3 \%)$ & $61.2(55.0-71.4 \%)$ & 58.2 \\
\hline
\end{tabular}

Int $\$$ international dollar, GDP gross domestic produce, $N A$ not applicable as costs were not estimated, $C S U C H$ Canadian Substance Use Costs and Harms, EU28 all countries of the European Union and the UK

${ }^{\text {a }}$ Study weight described the percentage of cost components included in the estimates, weighted for the relative contribution to total costs. 1 study weight could be interpreted as the degree of underreporting

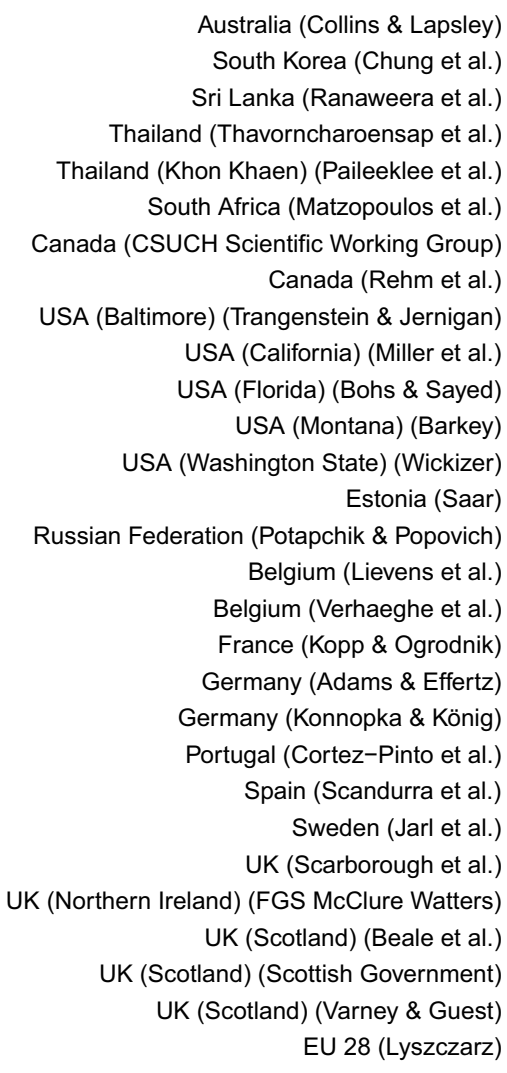

Australia (Collins \& Lapsley)

South Korea (Chung et al.)

Sri Lanka (Ranaweera et al.)

Thailand (Thavorncharoensap et al.)

(Kouth Africa (Matzopoulos et al.)

Canada (CSUCH Scientific Working Group)

Canada (Rehm et al.)

USA (California) (Miller et al.)

USA (Florida) (Bohs \& Sayed)

USA (Montana) (Barkey)

Estonia (Saar)

(Popchik \& Popovich)

Belgium (Lievens et al.)

Belgium (Verhaeghe et al.)

France (Kopp \& Ogrodnik)

Germany (Adams \& Effertz)

Germany (Konnopka \& König)

Portugal (Cortez-Pinto et al.)

Spain (Scandurra et al.)

Sweden (Jarl et al.)

(Scarborough et al.)

UK (Scotland) (Beale et al.)

(Scotland) (Scottish Government)

EU 28 (Lyszczarz)
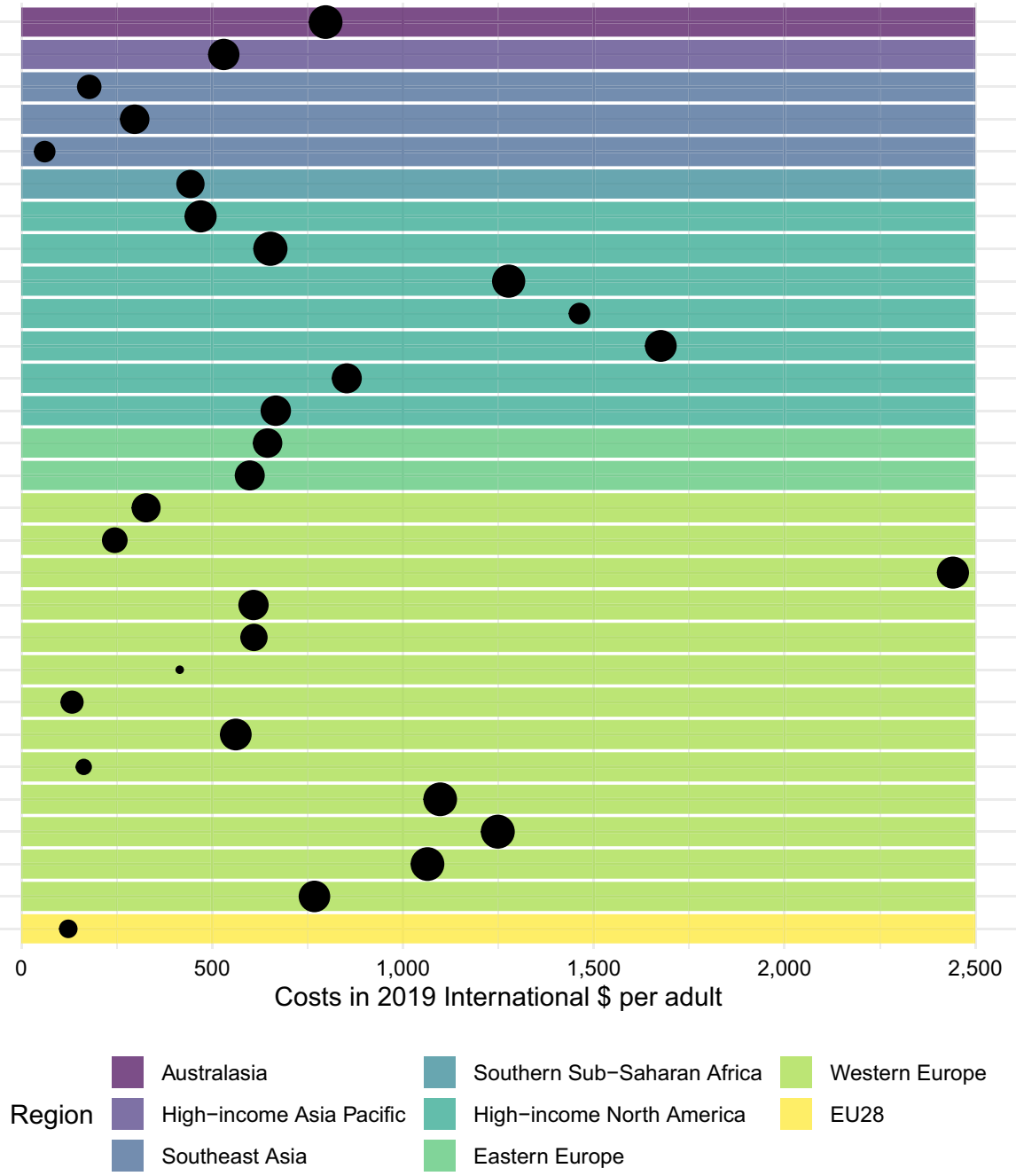

Western Europe

EU28
Eastern Europe

Fig. 1 Total costs presented in 2019 international dollars per adult (size of the data point represents study weight, with a larger size indicating inclusion of more relevant cost components). EU 28 all countries of the European Union and the UK) 
human capital approach, and in only four studies were other approaches (mostly friction cost) pursued in sensitivity analyses [23, 31, 39, 40] (for more details on the estimation methods of each study, see Costs_data_extraction.xlsx in ESM 3). Of 27 studies that provided indirect cost estimates, productivity losses due to premature mortality were most commonly estimated ( $n=23$ studies; $32.3 \%$ of all indirect costs; 95\% CI 26.7-37.9\%). In one study [28], the productivity losses due to premature mortality were calculated for 28 European countries, with estimates ranging from 22.4 Int\$ (Malta) to 235.8 Int\$ (Lithuania) per adult. Only three other indirect cost components were estimated by at least one-third of the studies: absenteeism ( $n=17$ studies; $8.0 \%, 95 \%$ CI
3.7-12.3\%), presenteeism ( $n=9$ studies; $14.8 \%, 95 \%$ CI $7.3-22.3 \%)$, and other indirect costs $(n=10$ studies; $12.1 \%$, 95\% CI 1.6-22.6\%).

\subsection{Correlation of the Two Cost Indicators}

Among the 26 studies that reported both direct and indirect costs, the two cost indicators, expressed as the percentage of the GDP and as 2019 Int\$ per adult, do correlate to a medium but not high extent (unweighted Pearson correlation $=0.595$; weighted Pearson correlation $=0.568$; see also supplementary Fig. 3 in ESM 1).

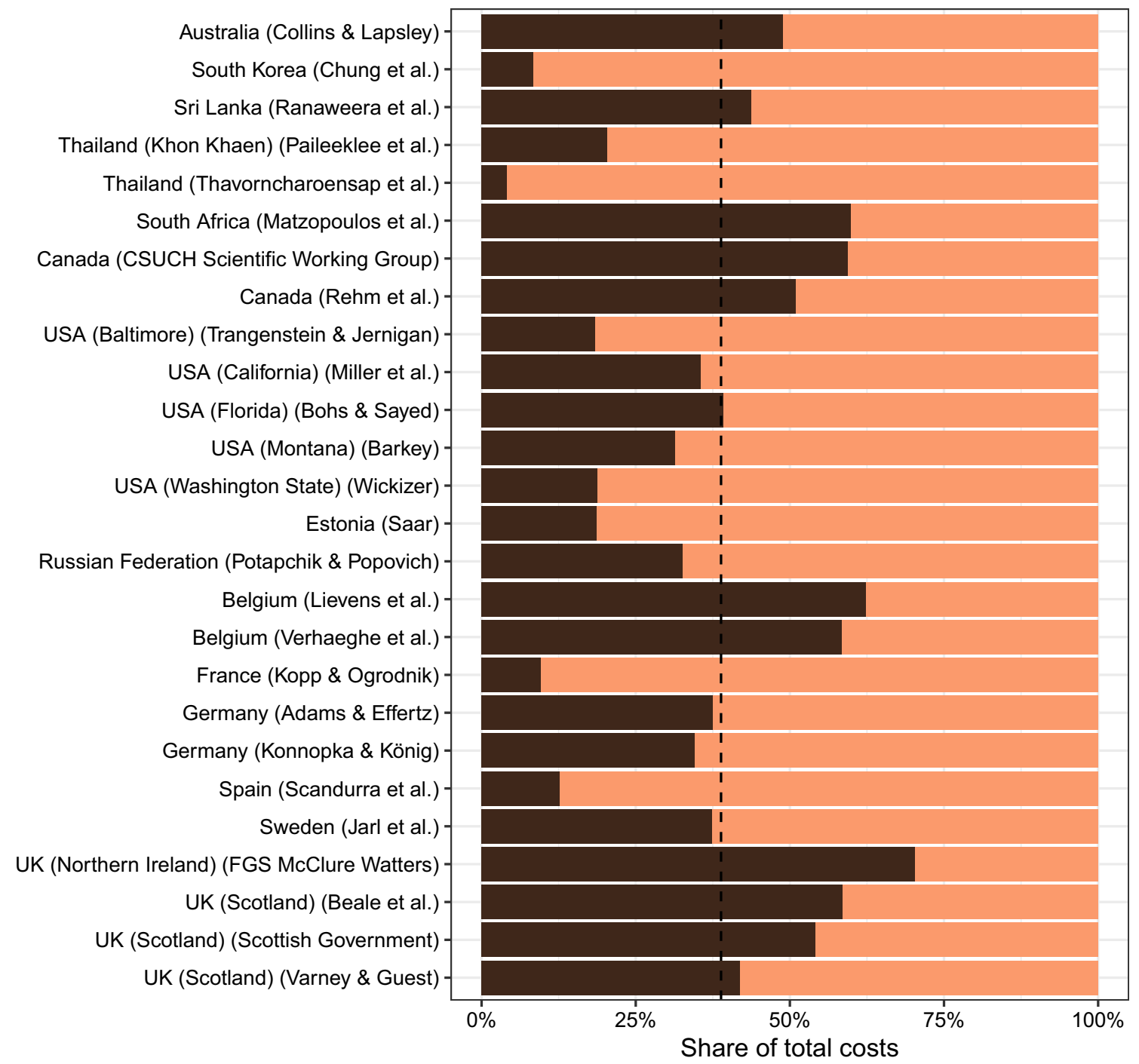

Cost source direct indirect

Fig. 2 Distribution of total costs per study for all studies that provided direct and indirect cost estimates (the vertical dashed line indicates the mean share of direct costs across all studies: $38.8 \%$ ) 


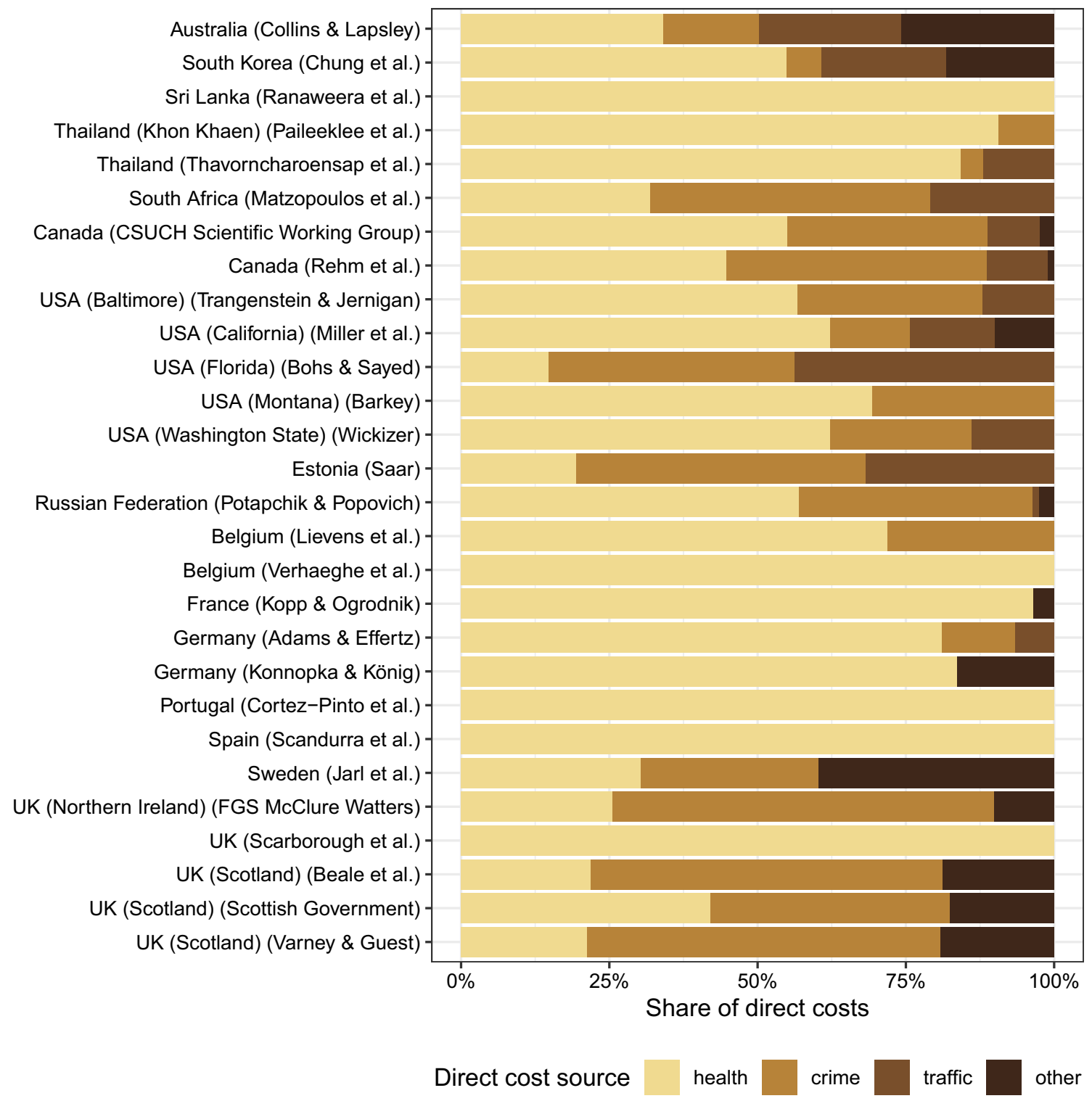

Fig. 3 Distribution of direct costs for all studies that provided direct cost estimates

\subsection{Estimating Costs in the Scenario of All Relevant Cost Drivers Being Considered}

In further analyses, we estimated the total alcohol-attributable tangible costs under the assumption that each study included all relevant cost components. If all cost components were to be considered, the tangible costs of alcohol consumption would amount to 1305.8 Int\$ per adult (95\% CI 873.3-1738.4), 1872.1 Int\$ per drinker (95\% CI 1278.8-2465.5), or equivalent to $2.6 \%$ (95\% CI 2.0-3.1) of the GDP. On average, only $58.2 \%$ of the alcohol-attributable tangible costs were considered in the identified studies.

\subsection{Association of Costs with Alcohol Consumption Variables}

Lastly, we examined the link of the two cost indicators with the annual amount of pure alcohol intake (in litres) per capita and per drinker as two different indicators for population alcohol exposure as a proxy for the causal driver for incurred costs (for total, direct, and indirect costs). As illustrated in supplementary Fig. 4 (see ESM 1), alcohol exposure was not clearly linked to both cost indicators, suggesting other unobserved factors to be more relevant for incurred costs than alcohol exposure itself. 


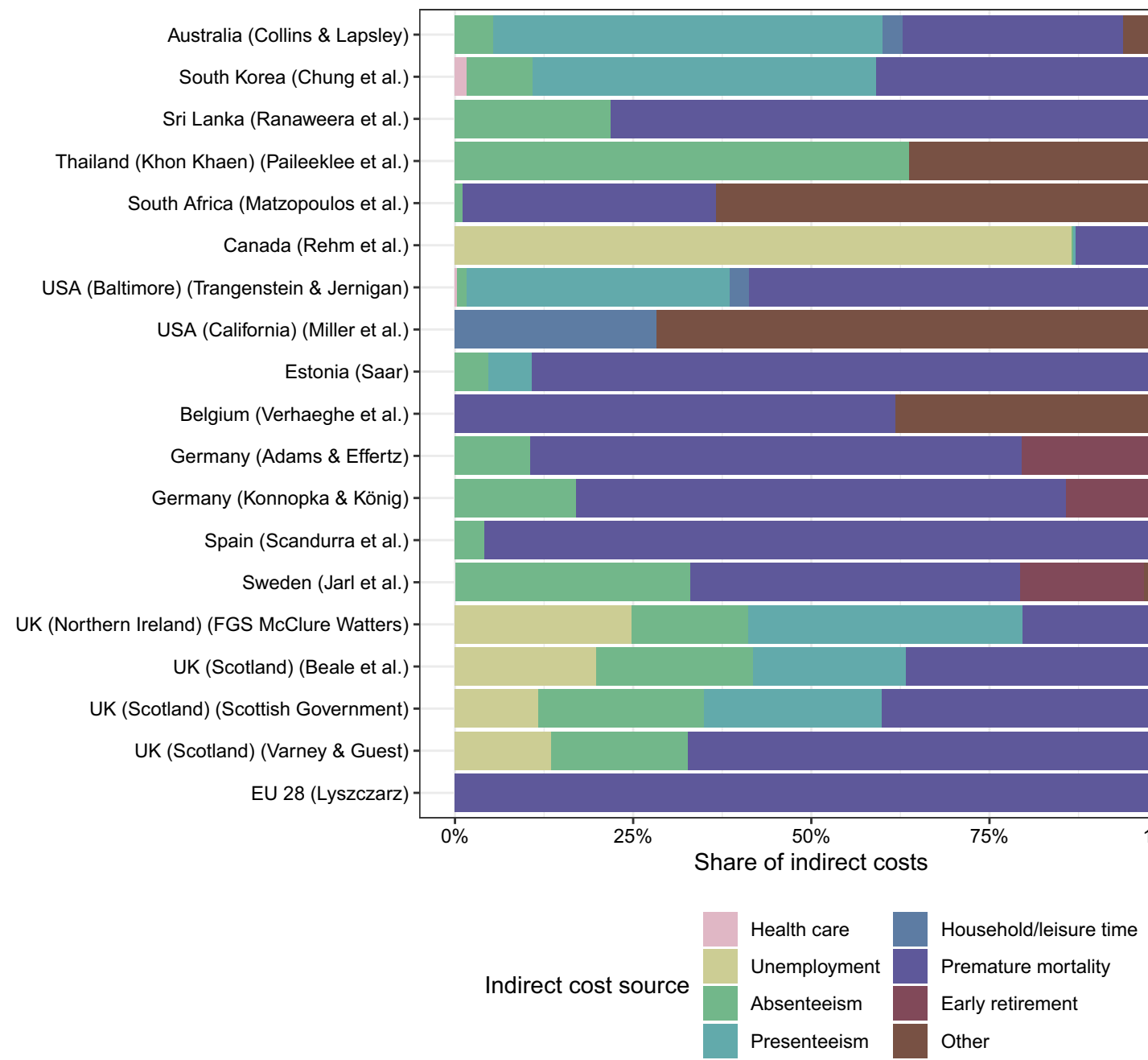

Fig. 4 Distribution of indirect costs for all studies that provided indirect cost estimates (i.e. studies that incompletely reported the distribution of indirect costs were excluded from this plot)

\section{Discussion}

\subsection{Summary of Main Findings}

Alcohol use continues to incur a high level of cost to modern societies. Despite numerous pleas to standardize the methodology (e.g. Møller and Matic [14]), we are still faced with a situation in which many different methodologies to estimate these costs have been used over the past decade [13]. We show that there is large variation in the studies with respect to which cost components are considered and that these differences should be accounted for. However, we also found methodological homogeneity, as nearly all studies followed a top-down approach, with indirect costs being calculated based on human capital assumptions.
In all studies examined in this study, alcohol use incurred substantial costs and, if all harms caused by alcohol were to be included, these costs are estimated to amount, on average, to 1306 Int\$ per adult or $2.6 \%$ of the GDP in the countries examined. As a consequence, the findings underscore and reiterate the message given by international organizations to reduce the use of alcohol [4].

\subsection{Strengths and Weaknesses}

This study not only summarized the total economic costs of alcohol consumption but also systematically quantified the contribution of various key cost components. Furthermore, this study is the first to overcome the limitations of previous reviews (e.g. Rehm et al. and Thavorncharoensap [8, 9]) related to methodological differences in cost estimation, 
thus eliminating a key barrier to compare costs across studies and countries.

While our search was systematic and we did not rely only on standard databases but also on expertise from other researchers, we may not have identified all relevant studies, which are often only published on government websites. Furthermore, the conclusions of any systematic review can only be as good as the underlying studies. As the risk assessment indicated, the overall quality of the studies was rated as being of medium quality, meaning that there are important areas to improve upon. For instance, only a few studies reported measures of uncertainty for selected estimates, which prohibits a complete meta-analytical summary of cost estimates. Furthermore, intangible costs were estimated in very different ways, again prohibiting meta-analytical aggregation. Lastly, indirect costs were mostly calculated following a human capital approach, which make the findings more comparable, but introduces the risk of overestimation costs as the underlying assumptions may not hold true. Costs calculated under the human capital approach heavily depend on the discount rate, yet there is no consensus on which rate is to be used [14]; thus, this will continue to be a limitation when comparing cost studies.

\subsection{Discussing Important Differences in Results with Other Studies}

We corroborate previous estimates, indicating that health care spendings only make up a fraction of total costs $(13 \%$ in the 2009 review; $18 \%$ in our study), while productivity losses are the main cost driver (72\% in the 2009 review; $61 \%$ in our study). Furthermore, our results, based on a larger number of studies from more recent years, are in line with total costs estimates of a 2009 review, according to which alcohol-attributable economic costs amounted to $2.5 \%$ and $2.1 \%$ of the GDP in high- and middle-income countries, respectively $[8,41]$. While these estimates overlap with our figures after adjustment for underreporting of omitted cost components, our unadjusted estimates are well below previous findings. This gap may be driven by three factors. First, the decline in drinking levels and attributable burden in many high-income countries [41, 42]; second, a lower study quality, i.e. exclusion of relevant cost components in more recent studies; and third, overproportional increases in the GDP relative to alcohol-attributable costs.

In fact, although comparing incurred costs with GDP is a common practice, we need to acknowledge several conceptual problems associated with this comparison. Most importantly, reporting health and crime costs, as well as productivity losses, as a 'GDP loss' is misleading, given that health and crime spending are themselves part of the GDP [14, 43]. While the percentage of GDP should not be interpreted as 'loss of GDP', this measure gives an approximate and comparable indication of the level of economic costs within a country. Based on a recommendation from an international expert group [44], we therefore kept this measure but complemented it with the measure on costs per adult, which can be standardized based on Int\$ and may be the preferred way of reporting.

\subsection{Novel Insights into Alcohol-Attributable Economic Burden}

In contrast to previous reviews on the economic burden of alcohol use, we provide several novel insights. First, we found cost estimates to be highly correlated within locations but less so within regions. We see two possible explanations for this finding. Any study seeking to estimate the economic burden from alcohol use will be informed by previous work, with a focus on studies that were conducted in the same location using similar data sources. For example, if governments mandate researchers to update previous estimates (see, for example, the paper by the Scottish Government [35]), changes to the estimation method ought to be kept to a minimum in order to allow for comparison of costs over time. Thus, such circumstances could explain why the same methodological approaches are maintained, even if they are incomplete, while guideline recommendations are not considered. Another plausible explanation relates to the fact that the value of goods depends largely on the local context (e.g. on governmental regulations, as well as supply and demand dynamics). In fact, variations in indirect costs, the main driver of total costs, are primarily driven by average wages, which are known to vary greatly between countries, even in rather homogenous regions with a common market, such as Europe. Standardizing the costs to Int\$ may have accounted for some, but not all, of the cross-country variations in the value of goods. On the contrary, applying inflation rates (as has been done in this study) is perhaps sufficient to remove major sources of within-country variation, resulting in high intraclass correlation.

Second, we found no clear link of alcohol exposure indicators to total costs; however, the relationship between alcohol exposure and adverse outcomes is more complex than one might initially assume. In fact, the same level of alcohol exposure will lead to higher burden in countries with lower levels of education, life expectancy and economic wealth [45]. As we did not account for these and other confounding factors in our analyses, the link between alcohol exposure may not be observable. Moreover, we do not have any external criteria for which to validate our weighting method against, thus we cannot say for certain that key methodological variations between studies were accounted for. Hence, unaccounted methodological differences between studies 
may have masked the underlying association between costs and alcohol exposure.

\subsection{Explanations of Results and Implications for Policymakers}

First and foremost, three main sectors are impacted by alcohol use: the health care sector, where alcohol use incurs major costs due to having causal impacts on more than 200 International Classification of Diseases (ICD) disease and injury categories $[8,46]$. Second, costs in the criminal justice sector even exceed the costs of health care in some countries (see Fig. 3). The high costs for criminal justice are a main reason why the overall costs in several countries (e.g. Canada [47]) exceed the costs of tobacco use, even if the latter causes a larger burden of disease in almost all countries around the world [1]. Third, considerable productivity losses indicate the importance of alcohol control measures for economic stability or growth. Premature mortality from alcohol consumption causes a sizable loss to society, both economically and socially. Moreover, impaired productivity at the workplace, either acutely or as a result of hangovers, is an important and perhaps overlooked adverse consequence of alcohol consumption [48, 49]. Our findings suggest costs from presenteeism to be about half that of health care costs, indicating the need to strengthen workplace alcohol prevention programmes [50]. Finally, we need to emphasize that the costs reported here represent the lower threshold of real costs. If intangible costs and costs from harms to others were included [51], the costs of alcohol use would be much higher. In one Australian study, the overall costs of alcohol use doubled once costs of harm caused to others were included [52].

Given the substantial costs of alcohol use to societies, the consumption of alcohol should be reduced, and there are evidence-based cost-effective alcohol control policies available to achieve this [53]. Given the high cost, higher excise taxation of alcohol seems to be the best choice as it will not only reduce the level of alcohol use and associated costs but in most cases will also increase tax revenues to the state [54].

\subsection{Implications for Future Research}

Given the limited comparability of cost studies and the implications discussed above, we suggest that funding for future cost-of-illness studies should be tied to adhering to methodological standards, such as imputing cost categories to achieve better comparability between studies [13, 14]. This could be best achieved by the use of standardized software (see the Canadian Centre on Substance Use and Addiction report [47] for an example of an application), which would allow us to use cost studies for monitoring purposes, to establish trends, and to evaluate policies; in other words, to use cost studies as per their original intent [14, 55]. Such an approach would not only further facilitate better comparability between countries but would also allow for benchmarking between countries, which is one of the major methodologies used to improve health care systems (e.g. Bennett et al. [56] for the area of non-communicable disease). It would also take away one of the major and repeated criticisms of cost studies [55], which we have addressed in this contribution. In fact, our findings suggest that current cost estimates are largely unrelated to the underlying alcohol exposure involved, and rather are driven by differences in methodology or by country-specific factors, rendering crosscountry comparisons rather meaningless.

\section{Conclusion}

Our findings show that the reported costs from alcohol consumption amount to an equivalent of 1.5-2.6\% of the study location's GDP, with the majority of costs due to productivity losses.

Supplementary Information The online version contains supplementary material available at https://doi.org/10.1007/s40273-021-01031-8.

Acknowledgements The authors thank Ms. Astrid Otto for copy editing this manuscript.

\section{Declarations}

Funding Open Access funding enabled and organized by Projekt DEAL. This study was funded by the German Ministry of Health, grant number ZMVI1-2518DSM210 (study title: "German economic cost analysis for alcohol use Part 1: Modeling (GECO-ALC1)"). The study funder had no role in the study design, data analysis, data interpretation, or writing of the manuscript.

Conflict of interest All authors have completed the International Committee of Medical Journal Editors (ICMJE) uniform disclosure form at www.icmje.org/coi_disclosure.pdf, and declare no support from any organization for the submitted work. Sören Kuitunen-Paul reports grants and non-financial support from the German Federal Ministry of Health (BMG), personal fees from IAP-TUD GmbH, Gesundheitsamt Dresden as funded by the German Federal Centre for Health Education (BzgA), Mabuse Verlag, and personal fees from a consortium funding a public speech (AbbVie Germany, Almirall Hermal, Belano Medical, Celgene, Janssen-Cilag, LEO Pharma, Lilly Germany, Novartis Pharma, Pfizer Pharma, UCB Pharma), as well as non-financial support from the College on Problems of Drug Dependence (CPDD), outside the submitted work. The authors have no other relationships or activities that could appear to have influenced the submitted work.

Availability of Data and Material All data are appended as supporting information.

Code Availability The code is appended as supporting information. 
Consent to participate Not applicable.

Consent for publication Not applicable.

Author Contributions Conceptualization: JM. Data curation: All authors. Formal analysis: JM. Funding acquisition: JM, SKP, JR. Investigation: All authors. Methodology: JM. Project administration: JM, JR. Resources: JM, JR. Software: JM. Supervision: JM, JR. Validation: JM, SAH, SC, CK, SKP. Visualization: JM, CK. Writing-original draft: JM. Writing - review and editing: All authors. JM is the guarantor and accepts full responsibility for the work and/or the conduct of the study, had access to the data, and controlled the decision to publish. All authors had full access to the full study data.

Open Access This article is licensed under a Creative Commons Attribution-NonCommercial 4.0 International License, which permits any non-commercial use, sharing, adaptation, distribution and reproduction in any medium or format, as long as you give appropriate credit to the original author(s) and the source, provide a link to the Creative Commons licence, and indicate if changes were made. The images or other third party material in this article are included in the article's Creative Commons licence, unless indicated otherwise in a credit line to the material. If material is not included in the article's Creative Commons licence and your intended use is not permitted by statutory regulation or exceeds the permitted use, you will need to obtain permission directly from the copyright holder. To view a copy of this licence, visit http://creativecommons.org/licenses/by-nc/4.0/.

\section{References}

1. GBD 2019 Risk Factors Collaborators. Global burden of 87 risk factors in 204 countries and territories, 1990-2019: a systematic analysis for the Global Burden of Disease Study 2019. Lancet. 2020;396(10258):1223-49.

2. Rehm J, Imtiaz S. Alcohol consumption as a risk factor for global burden of disease. A narrative review. Subst Abuse Treat Prev Policy. 2016;11(1):37.

3. Shield K, Manthey J, Rylett M, Probst C, Wettlaufer A, Parry $\mathrm{CDH}$, et al. National, regional, and global burdens of disease from 2000 to 2016 attributable to alcohol use: a comparative risk assessment study. Lancet Public Health. 2020;5(1):e51-61.

4. World Health Organization. WHO Global Coordination Mechanism on the Prevention and Control of NCDs: NCD and the Sustainable Development Goals. 2018. http://www.who.int/ global-coordination-mechanism/ncd-themes/sustainable-devel opment-goals/en/.

5. Rehm J, Casswell S, Manthey J, Room R, Shield K. Reducing the harmful use of alcohol: have international targets been met? Eur J Risk Regul. 2020. https://doi.org/10.1017/err.2020.84.

6. gov.uk. Alcohol's harm to others: an evidence review of the harm caused by alcohol to the people around those who are drinking. 2020. https://www.gov.uk/government/publications/alcoh ols-harm-to-others.

7. Graham K, West P. Alcohol and crime: Examining the link. In: Heather N, Peters TJ, Stockwell T, editors. International handbook of alcohol dependence and problems. Sussex: Wiley; 2001. p. 439-70.

8. Rehm J, Mathers C, Popova S, Thavorncharoensap M, Teerawattananon Y, Patra J. Global burden of disease and injury and economic cost attributable to alcohol use and alcohol-use disorders. Lancet. 2009;373(9682):2223-33.
9. Thavorncharoensap M, Teerawattananon Y, Yothasamut J, Lertpitakpong C, Chaikledkaew U. The economic impact of alcohol consumption: a systematic review. Subst Abuse Treat Prev Policy. 2009;4:20.

10. World Health Organization Regional Office for Europe. Fact sheet on the SDGs: alcohol consumption and sustainable development. 2020. https://www.euro.who.int/en/health-topics/disea se-prevention/alcohol-use/publications/2020/fact-sheet-on-thesdgs-alcohol-consumption-and-sustainable-development-2020.

11. Single E, Collins D, Easton B, Harwood H, Lapsley H, Kopp $\mathrm{P}$, et al. International guidelines for estimating the costs of substance abuse. Geneva: World Health Organization; 2003. Report No.: 9241545828.

12. Barrio P, Reynolds J, Garcia-Altes A, Gual A, Anderson P. Social costs of illegal drugs, alcohol and tobacco in the European Union: a systematic review. Drug Alcohol Rev. 2017;36(5):578-88.

13. Carr S, Rehm J, Manthey J. Guidelines and reality in studies on the economic costs of alcohol use: a systematic review. Int J Alcohol Drug Res. 2021. https://doi.org/10.7895/ijadr.283.

14. Møller L, Matic S. Best practice in estimating the costs of alcohol—recommendations for future studies. Copenhagen: WHO Regional Office for Europe; 2010.

15. PRISMA Transparent Reporting of Systematic Reviews and MetaAnalysis. Homepage 2015. http://www.prisma-statement.org/.

16. National Institute for Health Research (NIHR). PROSPERO: International prospective register of systematic reviews. York: University of York: Centre for Reviews and Dissemination; 2020. https://www.crd.york.ac.uk/prospero/.

17. The World Bank. PPP conversion factor, GDP (LCU per international \$) 2020. https://data.worldbank.org/indicator/PA.NUS.PPP.

18. Bates D, Mächler M, Bolker B, Walker S. Fitting linear mixedeffects models using lme4. J Stat Soft. 2015;67(1):1-48. https:// doi.org/10.18637/jss.v067.i01.

19. Lüdecke D, Makowski D, Waggoner P, Patil I. Assessment of regression models performance: easystats.github.io; 2020. https:// easystats.github.io/performance/.

20. R Core Team. A language and environment for statistical computing. R Foundation for Statistical Computing Vienna, Austria: R Foundation for Statistical Computing; 2020 [updated 17/12/2020. https://www.R-project.org/.

21. Jarl J, Johansson P, Eriksson A, Eriksson M, Gerdtham U-G, Hemström Ö, et al. The societal cost of alcohol consumption: an estimation of the economic and human cost including health effects in Sweden, 2002. Eur J Health Econ. 2008;9(4):351-60.

22. Lievens D, Vander Laenen F, Verhaeghe N, Putman K, Pauwels L, Hardyns W, et al. Economic consequences of legal and illegal drugs: the case of social costs in Belgium. Int J Drug Policy. 2017;44:50-7.

23. Matzopoulos RG, Truen S, Bowman B, Corrigall J. The cost of harmful alcohol use in South Africa. S Afr Med J. 2014;104(2):127-32.

24. Kopp P, Ogrodnik M. The social cost of drugs in France in 2010. Eur J Health Econ. 2017;18(7):883-92.

25. Konnopka A, König H-H. Direct and indirect costs attributable to alcohol consumption in Germany. Pharmacoeconomics. 2007;25(7):605-18.

26. Scarborough P, Bhatnagar P, Wickramasinghe KK, Allender S, Foster C, Rayner M. The economic burden of ill health due to diet, physical inactivity, smoking, alcohol and obesity in the UK: an update to 2006-07 NHS costs. J Public Health. 2011;33(4):527-35.

27. Cortez-Pinto H, Gouveia M, dos Santos Pinheiro L, Costa J, Borges M, Carneiro AV. The burden of disease and the cost of illness attributable to alcohol drinking - results of a national study. Alcohol Clin Exp Res. 2010;34(8):1442-9. 
28. Łyszczarz B. Production losses associated with alcohol-attributable mortality in the European Union. Int J Environ Res Public Health. 2019;16(19):3536.

29. Barkey PM. The economic cost of alcohol abuse in Montana. Missoula: University of Montana; 2009.

30. Beale S, Sanderson D, Kruger J, Glanville J, Duffy S, (York Health Economics Consortium). The societal cost of alcohol misuse in Scotland for 2007. Edinburgh: Scottish Government Social Research; 2010.

31. Bohs R, Sayed B. The annual economic impact of alcohol and drug use in Florida. Miami: Miami Behavioral Health Center; 2009.

32. FGS McClure Watters. Social costs of alcohol misuse in Northern Ireland for 2008/09. Belfast: Department of Health; 2010.

33. Miller TR, Nygaard P, Gaidus A, Grube JW, Ponicki WR, Lawrence BA, et al. Heterogeneous costs of alcohol and drug problems across cities and counties in California. Alcohol Clin Exp Res. 2017;41(4):758-68.

34. Paileeklee S, Kanato M, Kaenmanee S, McGhee SM. Alcohol drinking behaviour and economic cost incurred by users in Khon Kaen. J Med Assoc Thail. 2010;93:S38-44.

35. Scottish Government. Costs of alcohol use and misuse in Scotland. Scottish Government Edinburgh; 2008.

36. Trangenstein PJ, Jernigan DH. The health impact of alcohol on american cities: modeling the local burden of current alcohol use in one jurisdiction. J Urban Health. 2020;97(2):260-70.

37. Varney SJ, Guest JF. The annual societal cost of alcohol misuse in Scotland. Pharmacoeconomics. 2002;20(13):891-907.

38. Wickizer TM. State-level estimates of the economic costs of alcohol and drug abuse. J Health Care Finance. 2013;39(3):71-84.

39. Potapchik E, Popovich L. Social cost of substance abuse in Russia. Value Health Reg Issues. 2014;4:1-5.

40. Rehm J, Gnam W, Popova S, Baliunas D, Brochu S, Fischer B, et al. The costs of alcohol, illegal drugs, and tobacco in Canada, 2002. J Stud Alcohol Drugs. 2007;68(6):886-95.

41. Global Health Data Exchange (GHDx). GBD results tool for the global burden of disease 2017 study. Seattle: Institute for Health Metrics and Evaluation; 2020. http://ghdx.healthdata.org/gbdresults-tool.

42. Manthey J, Shield KD, Rylett M, Hasan OSM, Probst C, Rehm J. Global alcohol exposure between 1990 and 2017 and forecasts until 2030: a modelling study. Lancet. 2019;393(10190):2493-502.

43. World Health Organization. WHO guide to identifying the economic consequences of disease and injury. Geneva: WHO; 2008. http://www.who.int/choice/publications/d_economic_impact_ guide.pdf.

44. Manthey J. Study report. Figshare; 2020 [cited 29 Dec 2020]. https://figshare.com/articles/book/Study_report/13497150/1.

45. Shield KD, Rehm J. Societal development and the alcohol-attributable burden of disease. Addiction. 2021. https://doi.org/10.1111/ add. 15441.

46. Rehm J, Gmel GE Sr, Gmel G, Hasan OSM, Imtiaz S, Popova $\mathrm{S}$, et al. The relationship between different dimensions of alcohol use and the burden of disease-an update. Addiction. 2017;112(6):968-1001.

47. Canadian Substance Use Costs and Harms Scientific Working Group. Canadian Substance Use Costs and Harms
(2015-2017). (Prepared by the Canadian Institute for Substance Use Research and the Canadian Centre on Substance Use and Addiction). Ottawa, ON: Canadian Centre on Substance Use and Addiction; 2020. https://www.ccsa.ca/canadian-subst ance-use-costs-and-harms-2015-2017-report.

48. Tecco J, Jacques D, Annemans L. The cost of alcohol in the workplace in Belgium. Psychiatr Danub. 2013;25(Suppl 2):S118-23.

49. Sullivan T, Edgar F, McAndrew I. The hidden costs of employee drinking: a quantitative analysis. Drug Alcohol Rev. 2019;38(5):543-53.

50. Ames GM, Bennett JB. Prevention interventions of alcohol problems in the workplace. Alcohol Res Health. 2011;34(2):175-87.

51. Navarro HJ, Doran CM, Shakeshaft AP. Measuring costs of alcohol harm to others: a review of the literature. Drug Alcohol Depend. 2011;114(2-3):87-99.

52. Doran C, Jainullabudeen T, Room R, Chikritzhs T, Laslett A-M, Livingston $\mathrm{M}$, et al. How much does alcohol really cost Australian drinkers and others affected by drinking? Sydney: National Drug and Alcohol Research Centre, University of Sydney; 2010.

53. Chisholm D, Moro D, Bertram M, Pretorius C, Gmel G, Shield K, et al. Are the "best buys" for alcohol control still valid? An update on the comparative cost-effectiveness of alcohol control strategies at the global level. J Stud Alcohol Drugs. 2018;79(4):514-22.

54. Sornpaisarn B, Shield KD, Österberg E, Rehm J. Resource tool on alcohol taxation and pricing policies. Geneva: World Health Organization and others; 2017.

55. Mäkelä K. Cost-of-alcohol studies as a research programme. Nordic Stud Alcohol Drugs. 2012;29(4):321-43.

56. Bennett JE, Kontis V, Mathers CD, Guillot M, Rehm J, Chalkidou K, et al. NCD Countdown 2030: pathways to achieving Sustainable Development Goal target 3.4. Lancet. 2020;396(10255):918-34.

57. Collins D, Lapsley HM. The costs of tobacco, alcohol and illicit drug abuse to Australian society in 2004/05. Canberra: Department of Health and Ageing Canberra; 2008.

58. Chung W-J, Chun H-J, Lee S-M. Socioeconomic costs of alcohol drinking in Korea. J Prev Med Public Health. 2006;39(1):21-9.

59. Ranaweera S, Amarasinghe $\mathrm{H}$, Chandraratne N, Thavorncharoensap M, Ranasinghe T, Karunaratna S, et al. Economic costs of alcohol use in Sri Lanka. PLoS ONE. 2018;13(6):e0198640.

60. Thavorncharoensap M, Teerawattananon Y, Yothasamut J, Lertpitakpong C, Thitiboonsuwan K, Neramitpitagkul P, et al. The economic costs of alcohol consumption in Thailand, 2006. BMC Public Health. 2010;10(1):323.

61. Saar I. The social costs of alcohol misuse in Estonia. Eur Addict Res. 2009;15(1):56-62.

62. Verhaeghe N, Lievens D, Annemans L, Vander Laenen F, Putman $\mathrm{K}$. The health-related social costs of alcohol in Belgium. BMC Public Health. 2017;17(1):958.

63. Adams M, Effertz T. Volkswirtschaftliche Kosten des Alkoholund Tabakkonsums. In: Singer MV, Batra A, Mann K, editors. Alkohol und Tabak: Grundlagen und Folgeerkrankungen Stuttgart: Georg Thieme Verlag KG; 2010. p. 57-62.

64. Scandurra R. Social impact of abusive alcohol consumption in Spain. Consumption, cost and policies. Rev Esp Salud Publica. 2011;85:141-7. 


\section{Authors and Affiliations}

\section{Jakob Manthey ${ }^{1,2,3}$ (D) Syed Ahmed Hassan ${ }^{4,5}$ (D) Sinclair Carr ${ }^{2}$ (D) $\cdot$ Carolin Kilian $^{1}$ (D) - Sören Kuitunen-Paul ${ }^{6}$ (D) Jürgen Rehm ${ }^{1,2,4,7,8} \mathbb{D}$}

1 Institute of Clinical Psychology and Psychotherapy, Technische Universität Dresden, Chemnitzer Str. 46, 01187 Dresden, Germany

2 Center for Interdisciplinary Addiction Research (ZIS), Department of Psychiatry and Psychotherapy, University Medical Center Hamburg-Eppendorf (UKE), Martinistraße 52, 20246 Hamburg, Germany

3 Department of Psychiatry, Medical Faculty, University of Leipzig, Semmelweisstraße 10, 04103 Leipzig, Germany

4 Institute for Mental Health Policy Research, Centre for Addiction and Mental Health (CAMH), 33 Ursula Franklin Street, Toronto, ON M5S 2S1, Canada
5 Institute of Health Policy, Management and Evaluation, 155 College Street, 4th Floor, Toronto, ON M5T 3M6, Canada

6 Department of Child and Adolescent Psychiatry, Faculty of Medicine, Technische Universität Dresden, Fetscherstraße 74, 01309 Dresden, Germany

7 Department of Psychiatry, Dalla Lana School of Public Health, University of Toronto, 155 College Street, 6th Floor, Toronto, ON M5T 3M7, Canada

8 Department of International Health Projects, Institute for Leadership and Health Management, I.M. Sechenov First Moscow State Medical University, Trubetskaya str., 8, b. 2, 119992 Moscow, Russian Federation 